\title{
ESTUDIO FITOQUÍMICO Y ACTIVIDAD ANTIINFLAMATORIA DE LA Annona muricata L. (GUANÁBANA) DE CUZCO
}

\author{
Phytochemical study and anti-inflammatory activity of Annona muricata L. (Soursop) from Cuzco
}

Elizabeth M Poma ${ }^{1}$, Evelyn R Requis ${ }^{1}$, Gloria C Gordillo², César M Fuertes ${ }^{3}$

${ }^{1}$ Facultad de Farmacia y Bioquímica, UNMSM. ${ }^{2}$ Instituto de Investigación de Química, Biología, Microbiología y Biotecnología “Marco Antonio Garrido Malo”, Facultad de Farmacia y Bioquímica, UNMSM. ${ }^{3}$ Instituto de Ciencias Farmacéuticas y Recursos Naturales "Juan de Dios Guevara”, Facultad de Farmacia y Bioquímica, UNMSM.

\section{RESUMEN}

Con el fin de dar sustento científico al uso tradicional de las especies vegetales se estudió el extracto acuoso de las hojas secas de Annona muricata L. "guanábana", especie recolectada en la ceja de selva de Cuzco, la cual fue clasificada taxonómicamente en el Museo de Historia Natural de la Universidad Nacional Mayor de San Marcos. Mediante análisis fitoquímico se demostró la presencia de flavonoides, entre otros metabolitos. Se clasificó al extracto acuoso como no tóxico según el método de dosis límite para la determinación de toxicidad aguda, resultado que fue avalado con el estudio macroscópico de órganos realizado en la facultad de Medicina Veterinaria de la UNMSM. Con el empleo del método del edema plantar en ratas inducido por $\lambda$-carragenina, se demostró el extracto acuoso a una concentración de $1,5 \mathrm{mg} / \mathrm{kg}$ posee actividad antiinflamatoria significativa comparado con indometacina. El análisis estadístico se realizó por el método ANOVA a $95 \%$ de confianza.

Palabras clave: Annona muricata L., toxicidad aguda, actividad antiinflamatoria, flavonoides.

\section{SUMMARY}

To give scientific support to the traditional use of plants, was studied the aqueous extract of dried leaves of Annona muricata L. "Soursop", specie collected in the highlands jungle of Cuzco, which was classified taxonomically in the Natural History Museum of the UNMSM; Annona muricata L. revealed the presence of flavonoids and other metabolites. The aqueous extract was classified as non-toxic according to the method of dose limits for the determination of acute toxicity, result supported with the macroscopic study of organs made at the Faculty of Veterinary Medicine UNMSM. By employing the method of plantar edema induced by $\lambda$-carrageenan mouse model, the aqueous extract of Annona muricata L., at concentration of $1,5 \mathrm{mg} / \mathrm{kg}$, had significant anti-inflammatory efficacy compared to indomethacin. The statistical analysis was carried out by ANOVA at 95\% confidence.

Keywords: Annona muricata L., acute toxicity, anti-inflammatory activity, flavonoids.

\section{INTRODUCCIÓN}

El Perú es conocido por su inmensa riqueza en recursos naturales, la cual es una de las razones por la que se mantiene en forma muy activa y funcional la llamada "Medicina Tradicional", que sin embargo, requiere de sustento científico, para de esta manera rescatar y respaldar su uso.

Annona muricata L. es un árbol ampliamente distribuido en tierra firme americana y el Caribe ${ }^{(1,2)}$. En la localidad de Quillabamba, región Cuzco, a $1500 \mathrm{~m}$ de altitud, sus hojas son usadas tradicionalmente en forma de infusión para el alivio de la inflamación.

Fue objetivo demostrar el efecto antiinflamatorio del extracto acuoso de las hojas secas de Annona muricata L.

\section{MATERIALES Y MÉTODOS}

\section{Estudio fitoquímico}

\section{Preparación de la Muestra}

La especie vegetal fue recolectada en la localidad de Quillabamba-Cuzco. Este material fue llevado al museo de Historia Natural de la Universidad Nacional Mayor de San Marcos, donde fue clasificado taxonómicamente.

La desecación tuvo lugar en un ambiente bajo techo previamenteacondicionado, completándose el proceso en una estufa a $40^{\circ} \mathrm{C}$ hasta peso constante.

La muestra pulverizada se conservó en frascos color ámbar, cerrados herméticamente para el estudio fitoquímico y farmacológico.

\section{Preparación del extracto}

El extracto acuoso fue preparado en forma de infusión con 
de 300 gramos de hojas en polvo en un litro agua caliente.

\section{Marcha fitoquímica ${ }^{(3)}$}

La marcha fitoquímica se hizo con la finalidad de determinar la composición general de metabolitos, entre ellos los flavonoides.

\section{a) Estudio de Flavonoides}

Análisis cualitativo de flavonoides ${ }^{(4-6)}$ : Se utilizó el sistema BAW (n-BuOH: $\mathrm{AcOH}: \mathrm{H}_{2} \mathrm{O}, 4: 1: 5$ ), para el análisis cromatográfico, en papel Whatman № 1 $(11 \times 29 \mathrm{~cm})$ descendente a escala preparativa. Los cromatogramas fueron secados y observados a luz UV con y sin vapores de amoníaco, identificándose bandas fluorescentes de diferente coloración, las cuales se intensificaron o cambiaron de color luego de su exposición a vapores de amoníaco.

Las bandas cromatográficas fueron eluidas con metanol, para su estudio con la reacción de Shinoda con el fin de determinar la presencia de flavonoides y clasificarlos de acuerdo a la literatura.

Análisis cuantitativo de flavonoides totales por espectrofotometría UV-VIS ${ }^{(4,7)}$ : La cuantificación de flavonoides totales fue expresada como quercetina. Se elaboró una curva de calibración a diferentes concentraciones de quercetina utilizando acetato de potasio y nitrato de aluminio como reactivos de desplazamiento. La cuantificación se desarrolló por espectrofotometría UV-VIS.

b) Determinación de la toxicidad aguda por el método de dosis límite ${ }^{(8-9)}$

La determinación de la toxicidad aguda consistió en administrar $2 \mathrm{~mL}$ del extracto acuoso en dosis $25 \mathrm{~g}$, 200 $\mathrm{Kg}, 2000 \mathrm{mg}$ y $3000 \mathrm{mg}$, por única vez durante 24 horas. Se observó el comportamiento de los animales durante 14 días, se sacrificarón los animales por dislocación cervical y se evaluaron los principales órganos.

\section{c) Determinación de la actividad antiinflamatoria ${ }^{(10-14)}$}

Se realizo por el método del edema plantar inducido por $\lambda$-carragenina; para el diseño experimental se usaron ratas albinas machos, adquiridas en el Centro Nacional de Producción de Biológicos del Instituto Nacional de Salud (Chorrillos) con peso de $200 \pm 20 \mathrm{~g}$, las cuales fueron mantenidas en condiciones normales de humedad y temperatura en el bioterio de la Facultad de Farmacia y Bioquímica, proporcionándoles alimento y agua.

Se realizó un ensayo preliminar, para determinar la dosis adecuada partiendo de la dosis tradicionalmente usada, en la localidad de Quillabamba. Se agruparon las ratas albinas en 3 grupos: Grupo control: agar-agar;
Grupo patrón: indometacina $5 \mathrm{mg} / \mathrm{Kg}$ en agar-agar y Grupo droga: extracto acuoso de Annona muricata L.

El porcentajede inhibición de la reacción inflamatoria a la carragenina, se calculó con siguiente fórmula ${ }^{(14-1)}$ :

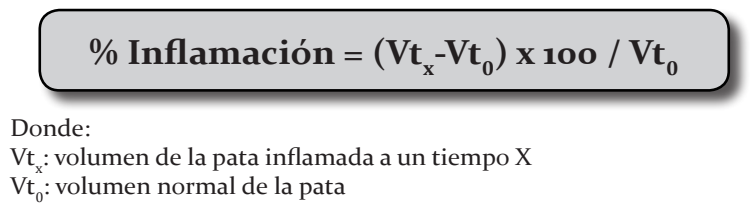

Análisis estadístico ${ }^{(16,17)}$

Inflamación residual (IR)

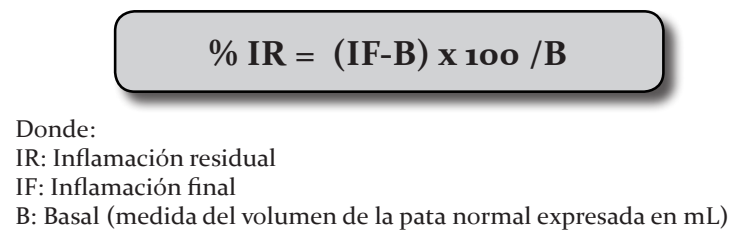

Eficacia antiinflamatoria (EA)

$$
E A=\left[\left(B / B_{0}-V / V o\right) / B / B_{0}\right] \times 10 o
$$

Donde:

$\mathrm{B} / \mathrm{B}_{0}=$ Es el incremento del volumen del blanco debido a la inflamación, con respecto al volumen inicial $\left(\mathrm{B}_{0}\right)$ del mismo.

$\mathrm{V} / \mathrm{V}_{0}=$ Es el incremento estandarizado de volumen inflamado, pero tratado con un agente antiinflamatorio.

$\mathrm{EA}=$ Es la disminución porcentual del volumen causado por la inflamación, para cada momento de observación experimental.

Estos datos servirán para el análisis estadístico ANOVA.

\section{RESULTADOS}

\section{a) Estudio de flavonoides}

Según el screening fitoquímico, Annona muricata L. contiene carbohidratos, compuestos polifenólicos, flavonoides, esteroides libres, saponinas y alcaloides.

Los resultados del análisis cromatográfico así como el comportamiento cromogénico de las bandas de los cromatogramas frente a la luz ultravioleta se presentan en la tabla 1.

\section{Cuantificación de flavonoides totales por} espectroscopía $U V$

En promedio, se obtuvo una concentración de 3,167 $\mu \mathrm{g} / \mathrm{mL}$ de flavonoides totales expresados en forma de quercitina.

\section{b) Estudio farmacológico}

Determinación de la toxicidad aguda por el método de dosis límite

En el ensayo de toxicidad aguda no se produjeron muertes ni signos de toxicidad posteriores a la administración. El 
incremento de peso fue estadísticamente similar en los grupos de ambos sexos respecto al grupo control. La necropsia no arrojó ninguna alteración macroscópica en órganos y tejidos examinados. El peso promedio en las ratas de los cuatro grupos se mantuvo entre 20 y $25 \mathrm{~g}$ sin mayor variación.

\section{c) Actividad antiinflamatoria}

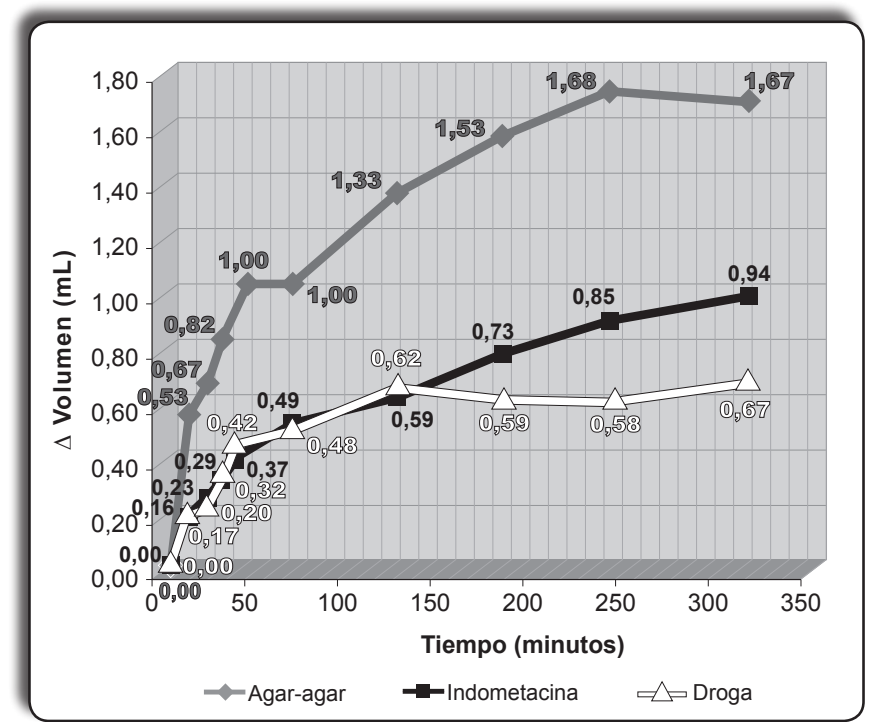

Figura 1. Curva comparativa del volumen de la pata inflamada.

Evaluación estadística de la inflamación residual Se realizó el análisis estadístico de ANOVA con 95\% de confiabilidad para los tratamientos de cada grupo -control, patrón y grupo droga-. Los resultados obtenidos fueron estadísticamente diferentes.

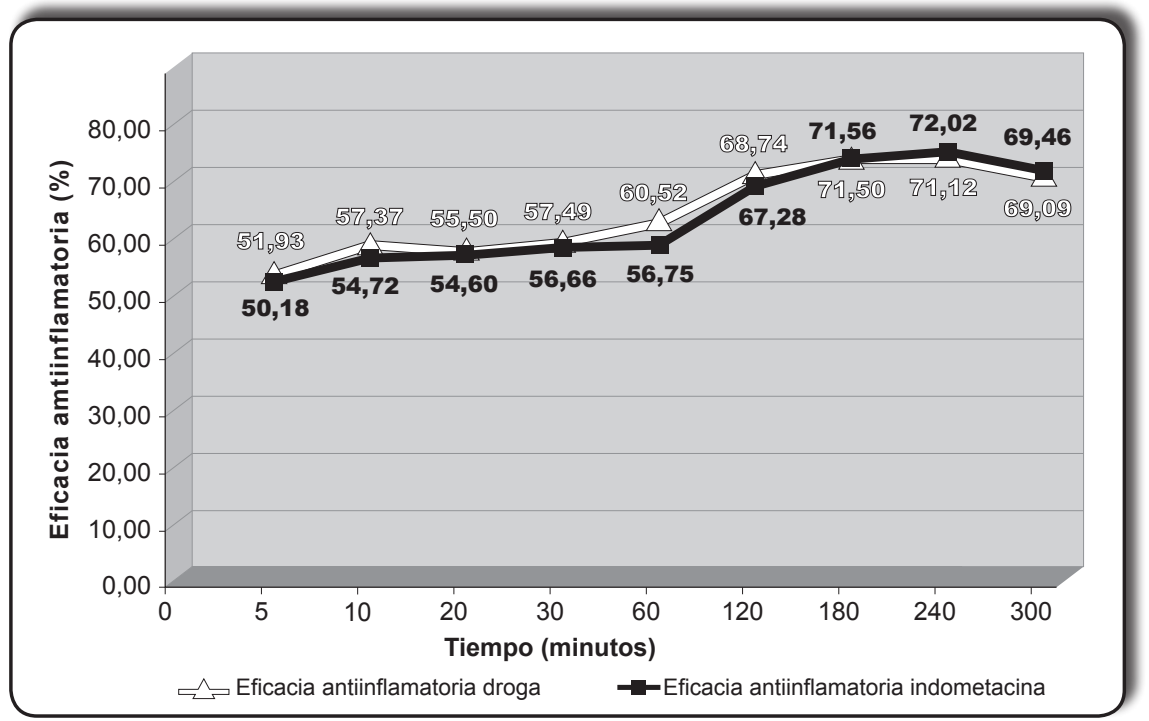

Figura 2. Eficacia antiinflamatoria de la indometacina y el extracto acuoso de hojas secas de Annona muricata L.

\section{DISCUSIÓN}

El extracto acuoso de Annona muricata L, comparado con los extractos acuosos de las especies Annona cherimolia, Annona reticulata y Annona squamosa, estableciendo la presencia de carbohidratos, alcaloides, taninos, compuestos polifenólicos y flavonoides ${ }^{(18,19)}$

Martino y Giraldo, en sus estudios, relacionan la presencia de flavonoides con la actividad antiinflamatoria por inhibición de la peroxidación del ácido araquidónico, determinando así, que los flavonoides, son los posibles responsables de la actividad antiinflamatoria ${ }^{(20,21)}$

La cuantificación de flavonoides totales se expresó como quercetina, que es un flavonoide tomado como referencia para la cuantificación, procedimiento descrito Lock ${ }^{(4)}$, encontrando 2,302 $\mu \mathrm{g}$ de flavonoides por $\mathrm{mL}$ de extracto; este resultado es menor al hallado en Annona cherimolia que fue de 6,07 mg, en extracto liofilizado.

El grupo droga presentó disminución del edema pedal en comparación con el grupo control alcanzando un efecto antiinflamatorio de 56,75\% , valor cercano al $60,52 \%$ de la indometacina; en la tercera hora el efecto se incrementó a $71,56 \%$, superando al $71,50 \%$ de la indometacina para el mismo periodo de tiempo; y finalmente alcanzó su valor máximo a la cuarta hora con $72,02 \%$ comparado con $71,12 \%$ de la indometacina. Los datos obtenidos fueron analizados estadísticamente con $95 \%$ de confianza y se concluyó que había diferencia significativa entre los grupos de tratamiento con la muestra problema, la sustancia estándar y el blanco.

Las actividades antiinflamatorias de Uncaria tomentosa Wild D.C. $83,3 \%{ }^{(13)}$, Cestrum auriculatum "Yerba santa" 50,58\% (22), Plantago major "Llantén" 30,8\% (23), Grias peruviana Miers $12,11 \%$ (11), Lupinus condensiflorus G.P. Smith-Talabra de 79,81\% (11), Avherroa carambola L. $64,27 \%$ (24) demostraron que la especie Annona muricata L. "guanábana", posee una eficiencia antiinflamatoria significativa. 
Tabla 5. Costo mínimo y máximo por ciclo de tratamiento según esquema terapéutico y diagnostico.

\begin{tabular}{|c|c|c|c|}
\hline Bandas & $\begin{array}{l}\text { Observación al } \\
\text { natural sin } \mathrm{NH}_{3}\end{array}$ & $\begin{array}{l}\text { Observación } \\
\text { con } \mathrm{NH}_{3}\end{array}$ & Posibles flavonoides \\
\hline AM1 & \multirow{2}{*}{ Celeste } & Amarillo limón & $\begin{array}{l}\text { Flavonas y flavononas sin 5-OH libre } \\
\text { Flavonoles sin 5-OH libre y con 3-OH substituido }\end{array}$ \\
\hline AM2 & & Celeste fluorescente & Isoflavonas carentes de 5-OH libre \\
\hline AM3 & \multirow{2}{*}{ Púrpura } & Celeste & 5-OH flavanona \\
\hline AM4 & & Rosado morado & \\
\hline AM5 & Amarillo & Naranja & Aurona con 4'-OH libre y algunas Chalconas 2- ó 4- $\mathrm{OH}$ \\
\hline AM6 & Púrpura & Morado & $\begin{array}{l}\text { Flavonas o flavonoles } 3-0 \text { substituidos, con } 5-\mathrm{OH} \text { pero sin } 4^{\prime}-\mathrm{OH} \text { libre } \\
6-\mathrm{o} 8-\mathrm{OH} \text { flavonas y 3-0 substituidos Flavonoles con } 5-\mathrm{OH}\end{array}$ \\
\hline AM7 & Celeste & Celeste blanquecino & Isoflavonas carentes de 5-OH libre \\
\hline
\end{tabular}

\section{CONCLUSIONES}

En el screening fitoquímico del extracto acuoso se encontraron polifenoles, taninos, esteroides, alcaloides y saponinas. Se hallaron también flavonoides en un valor de 2,302 $\mu$ g expresados como quercetina por $\mathrm{mL}$ de extracto.

La dosis administrada de $1,5 \mathrm{mg} / \mathrm{kg}$ de peso del extracto acuoso de hojas secas de Annona muricata L. produjo un efecto antiinflamatorio, con eficacia del 53,18\% en comparación con la indometacina.

El extracto acuoso de Anona muricata L. no presentó toxicidad aguda según el método de la dosis límite.

\section{REFERENCIAS BIBLIOGRÁFICA}

1. Brack A. Diccionario Enciclopédico de plantas útiles del Perú. Editorial PNUD. Cuzco, 1999. p. 38-40.

2. Desmarchelier C, Witting F. Sesenta plantas medicinales de la Amazonia peruana. $1^{a}$ ed. Editorial Gráfica Bellido. Lima, 2000. p.57-9.

3. Gorriti A. et al. Manual de farmacognosia y productos naturales terapéuticos. UNMSM. Lima, 1993.

4. Lock de Ugaz O. Investigación Fitoquímica: método en el estudio de productos naturales. Fondo Editorial de la Pontificia Universidad Católica, PUEP. Lima, 1988.

5. Martínez A. Flavonoides. Facultad de Química Farmacéutica. Universidad de Antioquia. Medellín, 2005.

6. Torres $\mathrm{O}$, et al. Estudio químico y obtención de principios químicosactivosdela especie Rollinia pittieri(Annonaceae) del Alto Ainu. Scientia Technica 2007; 33: 55-8.

7. Lock de Ugaz O. Análisis de flavonoides. Lima Fondo Editorial de la Pontificia Universidad Católica, PUEP. 2006.

8. Cotillo P, Rojas R. Métodos farmacológicos en la investigación de productos vegetales. Editorial Gráfica Jiménez. Lima, 1990.
9. Programa Iberoamericano de Ciencia y Tecnología para el Desarrollo. Manual de Técnicas de Investigación. 1995.

10. Sugishita E, et al. Antiinflamatory testing methods: comparative evaluation of mice and rats. J Pharm Dyn 1981; 4: 565-75.

11. Cáceres H, Gamarra E. Estudio fitoquímico y determinación de la actividad antiinflamatoria de Lupinus condensiflorus GP. Smith-Talabra. [Tesis para optar el título Profesional de Químico Farmacéutico] Universidad Nacional Mayor de San Marcos. Lima, 1999.

12. Kodaka R, Miyashiro G. Estudio fitoquímico, determinación de la actividad antimicrobiana y antiinflamatoria de Grias peruviana Miers-Sacha mango. [Tesis para optar el título Profesional de Químico Farmacéutico] Universidad Nacional Mayor de San Marcos. Lima, 1998.

13. Rengifo D, Gomes E. Estudio comparativo del efecto antiinflamatorio de varias muestras de Uncaria tomentosa Wuild D.C. [Tesis para optar el título Profesional de Químico Farmacéutico] Universidad Nacional Mayor de San Marcos. 1997.

14. Winter $C$, et al. Carrageenin-induced edema in hind paw of the rat as an assay for antiinflamatory Drugs. Proc Soc Exp Biol Med 1962; 111: 544-7.

15. Salama A, et al. Actividad antiinflamatoria, dosis letal 50 y estudio fitoquímico preliminar de Cucumis anguria. Revista Colombiana de Ciencias Químico-Farmacéuticas 1994; 22: 42-46.

16. Flores D, et al. Modelos animales de enfermedad. Ensayos farmacológicos in vivo. $1^{\mathrm{a}}$ ed. UNSLG. Lima, 2005.

17. Canavos G. Probabilidad y estadística: aplicaciones y métodos. 1a ed. McGraw Hill. México DF, 1995.

18. Padhi LP, Panda SK, Sataphaty SN y Dutta SK. In vitro evaluation of antibacterial potential of Annona squamosa L. and Annona reticulata L. from Similipal Biosphere Reserve, Orissa, India. Journal of Agricultural Technology 2011; 7(1): 133-42.

19. Fuertes $C$ et al. Estudio Integral de Plantas Biocidas del Algodonero. Ciencia e Investigación 2010; 13(1):34-41.

Los corchetes para citar trabajos de tesis, sean de titulación, doctorales o especialistas, suelen ser considerados dentro del estilo Vancouver, que la revista emplea. Los corchetes para este tipo de referencias, se han aplicado en diversos artículos, tanto en ediciones previas como en la presente, de Ciencia e Investigación. 
20. Martino V. Los flavonoides como promisorios agentes preventivos y terapéuticos. Acta Farm Bonaerense 2000; 19(4): 303-8.

21. Giraldo Let al. Actividad antinitrosativayantiinflamatoria de los flavonoides de las hojas de Uncaria tomentosa Willd D.C. (Uña de gato). Revista Sociedad Química del Perú 2003; 4(69): 229-42.

22. Aguado I. Estudio fitoquímico, determinacion de la actividad antimicrobiana y antiinflamatoria de Cestrum auriculatum L. "Yerba santa" [Tesis para optar a título Profesional de Químico Farmacéutico] Universidad Nacional Mayor de San Marcos. Lima, 1997.

23. Loayza, D. Efecto antiinflamatorio del extracto acuosos de Plantago major "Llantén". [Tesis para optar el título Profesional de Químico Farmacéutico] Universidad Nacional Mayor de San Marcos. Lima, 1991.
24. Wendell G. y Palacios M. Estudio farmacognóstico y actividad antiinflamatoria del fruto de Averrhoa carambola L. [Tesis para optar a título Profesional de Químico Farmacéutico] Universidad Nacional Mayor de San Marcos. Lima, 2003.

Manuscrito recibido el: 24/10/11

Aceptado para su publicación el: 04/01/2012

\section{Correspondencia:}

Nombre: Cesar Máximo Fuertes Ruiton

Dirección: Jr. Puno 1002- Lima 1 - Perú

e-mail: cfuertesr@unmsm.edu.pe 